Article

\title{
The Impact of Fairness Concerns on the Formation of Retailers Alliance with Consideration of Transshipment
}

\author{
Xiaohong Yu *, Sujuan Wang and Xindong Zhang \\ School of Economics and Management, Shanxi University, Taiyuan 030006, China; \\ wangsujuan-1981@163.com (S.W.); zhangxd@sxu.edu.cn (X.Z.) \\ * Correspondence: yxhhappy1985@163.com
}

Received: 16 December 2018; Accepted: 26 January 2019; Published: 29 January 2019

check for updates

\begin{abstract}
This paper investigated the impact of fairness concerns on the formation of the inventory transshipment strategy alliance through its impact on the ordering decisions and profits of two retailers. The paper introduced reference point dependency to describe the retailer's fairness concerns utility function, and modeled the strategic alliance system consisting of two retailers involved in transshipment. The conditions for the existence of Nash equilibrium solutions were given. The paper solved the impact of the fairness parameters on order quantities and profits by the implicit function theorem. Based on the theoretical analysis and numerical examples, this paper investigated the formation of a strategic alliance under asymmetric and symmetric fairness concerns. The results are as follows: (1) under asymmetric fairness concerns, when the transshipment price of the retailer with no fairness concerns is no more than the transshipment price of the retailer with fairness concerns, an inventory transshipment strategy alliance can be formed. Otherwise the retailer with no fairness concerns may need to pay the retailer with fairness concerns certain fees in order to form a strategic alliance; (2) under symmetric fairness concerns, two completely symmetric retailers can form strategic alliances.
\end{abstract}

Keywords: strategy alliance; inventory transshipment; fairness concerns; sustainable operation; newsvendor model

\section{Introduction}

Traditional sustainable supply chain management usually focuses on the three dimensions of finance, society and environment, whereas this cognition is being extended at present due to the current dynamic market environment. A dynamic and uncertain business environment and the growing complexity of globalization have imposed unexpected and inevitable risks to supply chains, even leading to supply chain disruptions. In such an uncertain business environment, sustainable operation has become an increasingly important topic. Kleindorfer et al. [1] argued that sustainable operations management must help companies become agile, adaptive, and aligned in today's turbulent and fast-changing business environment. Sustainable operational management literature is now beginning to explore the best way to build resilience into supply chains in an uncertain business environment, and the relational research is still in its infancy.

As the uncertainty of market demand is also getting stronger, it is difficult for enterprises to accurately predict market demand. Thus, the demand uncertainty can increase a retailer's risk of overstock and understock. Many products are characterized by a short sales cycle and strong timeliness, such as fast fashion products, electronic products, newspapers and festival products. On one hand, if these products are not sold within the effective period, they have to be sold at a lower price or regarded as waste after expiration. On the other hand, if out of stock, it is often difficult to organize 
production in time. This kind of supply-demand mismatch often results in serious losses to the supply chain. Therefore, it is very important to eliminate or reduce the mismatch between supply and demand. To address this issue, this paper argues that inventory transshipment could provide an efficient mechanism for correcting mismatches between uncertain demands and their available inventories to contribute to the sustainable operation of the supply chain as a whole [2-4]. More specifically, the retailers located in different regions adopt the inventory transshipment strategy to share inventory risk and cope with uncertain market demand, improving customer service levels and supply chain operational efficiency [5-8]. With the popularity of electronic information management systems, inventory transshipment has become a common strategy for some retailers to adopt and has been widely used in retail industries, such as automobiles, computers, clothing, etc. For example, Caterpillar, a large equipment manufacturer, sells its products through a retailer's distribution network, and provides retailers with an inventory sharing information system to assist retailers in providing better inventory control and after-sales service. Retailers use a query system to obtain inventory information and adopt the transshipment strategy, which can better match uncertain supply and demand, and improve the sales of the company and the service levels to customers [8]. All these practices essentially lead to the improvement of sustainable operational efficiency across the whole supply chain.

Most research from a myopic viewpoint focuses on optimal ordering decisions when inventory transshipment is adopted and how the transshipment profits are distributed [2-7]. However, the literature has paid little attention to the sustainability and the stability of cooperation relationship in a farsighted sense $[9,10]$. Strategic alliances can be useful tools through which firms achieve stable cooperation and competitive advantage. In reality the retailers concerned about fairness are an important factor influencing stable cooperation and their sustainable operation [11]. That is, the retailers consider not only their immediate payoffs but also how other retailers respond to their actions [12]. Therefore, when retailers cooperate to form inventory transshipment alliances, they also tend to act with fairness concerns. In the inventory transshipment alliance, they cooperate when they feel it is fair to do so; when they feel cooperation is unfair, they are even willing to punish the other partner at some cost, that is, they don't form the inventory transshipment strategic alliance with each other.

In light of this, our research tries to address the following problems: (1) how do fairness concerns influence the order quantities and profits of retailers utilizing transshipment? (2) under fairness concerns, what is the condition for the formation of an inventory transshipment strategic alliance? To answer the above questions, we introduced reference point dependency to describe the retailer's fairness concerns using the utility function, modeled a system consisting of two retailers with transshipment, and solved the optimal order quantities of two retailers respectively in two different scenarios of asymmetric and symmetric fairness concerns. Also, the conditions for the existence of Nash equilibrium solutions were given. On this condition, we studied the influence of the retailer's fairness parameters on its order quantities and profits by using the implicit function theorem, and compared the profits of retailers under asymmetric and symmetric fairness concerns respectively with the corresponding profits under the scenario of complete rationality.

This research makes three contributions to the literature. (1) Fairness concerns are introduced to the context of inventory transshipment strategic alliance, expanding the research field and scope of organizational justice theory. (2) Previous research on inventory transshipment focused on the optimal ordering decision when inventory transshipment is adopted and how the transshipment profits are distributed, which is rarely studied from the perspective of a strategic alliance. (3) Previous studies on inventory transshipment are based the assumption that economic agents are completely rational, and few studies are conducted from the perspective of behavioral and social preference.

The rest of this paper is organized as follows. Section 2 provides a review of relevant literature. Section 3 shows the model description and the benchmark model, and Section 4 presents the introduction of fairness concerns and their impact on order quantities and profits. Section 5 gives some 
numerical examples to illustrate our results more intuitively. Section 6 summarizes the conclusions and discusses limitations and future research. All proofs are relegated to Appendix A.

\section{Literature Review}

In this section, we provide a brief review of literature related to our work. This paper reviews three areas of existing research: strategic alliance, inventory transshipment and fairness concerns.

\subsection{Strategic Alliance}

With the acceleration of the globalization of technology, information and finance, many companies expect to choose strategic alliances that are in line with their own development and further achieve resource sharing and maintain competitive advantages through negotiation. Some scholars have studied the factors that influence the formation of these strategic alliances. Reuer and Lahiri believed that the impact of geographic distance depends on the extent to which partners can evaluate each other's resources and prospects, and taking the experience of R\&D cooperation in the semiconductor industry as an example, and found that the possibility of R\&D alliance formation was negatively correlated with geographical distance [13]. Blevin and Ragozzin found that the experience of going public for venture capital firms and companies owned by venture capital firms has an important impact on the formation of alliances of venture companies, and when the exit outcome is an acquisition, rather than going public, venture capital firms more actively formed alliances [14]. Gu and Lu pointed out that a company's reputation affects the company's behavioral tendency to form alliances through the empirical analysis of China's venture capital industry, and the relationship presents an inverted U-shaped curve [15]. Although the single alliance relationship plays its role, enterprises will simultaneously build, maintain and manage the alliance combination which is formed with multiple partner enterprises in the real market environment. Bos et al. focused on the impact of the alliance portfolio concentration ratio on the performance of focal companies. They pointed out that in a relatively small alliance portfolio, an increase of the alliance portfolio concentration ratio was positively correlated with their financial performance [16]. Wassmer and Madhok based on data from the global aviation industry, found that resource balance at the portfolio level helps airlines to improve performance, and pointed out that managers should be careful to obtain excessive resources through a few partners [17]. Jiang et al. studied how network constraints (network cohesion) of the alliance affect a company's alliance with new members and found that when a company's alliance members are closely connected to each other, a cohesive network often encourages and hinders the company from adding new alliance members [18].

\subsection{Inventory Transshipment}

At present, the research on inventory transshipment is mainly focused on two types of issues. One issue is to study the optimal order quantities of retailers when taking inventory transshipment. Under a centralized decision-making process, taking Krishnan and Rao as the representative, they considered the optimal ordering decision for inventory transshipment within a parent company [2]. On this basis, Abouee-Mehrizi et al. [19] and Glazebrook et al. [20] extended the study to multiple cycles. With the gradual evolution of business model towards decentralization, scholars began to study the situation of independent retailers' inventory transshipment. Rudi et al. studied the optimal ordering levels of two independent retailers for inventory transshipment and analyzed the sensitivity of transshipment prices to economic parameters [5]. Sosic pointed out that in the case of $\mathrm{N}$ independent retailers for transshipment, when a farsighted retailer used Shapley values to allocate transshipment revenue, joint inventory sharing among all retailers as a whole was an option to maximize profit distribution and the result of the alliance was both farsighted and stable, with nonidentical unit additional revenues [9]. Another option is to further expand the distributed business model into the context of supply chain and study the impact of inventory transshipment on the profits of manufacturers and retailers in the supply chain. Dong and Rudi considered a supply chain system 
consisting of one manufacturer and multiple all-in-one retailers, and studied the impact of inventory transshipment of the decentralized retailers on manufacturers and retailers' profits under the condition of endogenous and exogenous wholesale prices [6]. Shao et al. considered the system of a manufacturer and multiple retailers according to the decentralized decision of upstream and downstream members in the supply chain, and studied the impact of inventory transshipment among dispersed retailers on the profits of upstream and downstream enterprises in the supply chain [7]. Zhao et al. found that the inventory transshipment strategy under the $\mathrm{O} 2 \mathrm{O}$ business model can coordinate the dual-channel supply chain [21].

\subsection{Fairness Concern}

Over the last few decades, the theoretical development of organizational justice has grown to include the distributive, procedural, interpersonal, and informational dimensions from a holistic concept to a multi-dimensional concept [22]. The various dimensions of fairness have been studied in the context of strategic alliances [23], distribution channels [24] and supply chain relationships [25]. Cui et al. were the first to model fairness concerns in the context of supply chain coordination. They found that a constant wholesale price will coordinate the supply chain [26]. Ho et al. studied the interactive effects of distributional and peer-induced fairness concerns on the performance of supply chains in a system consisting of a supplier and two retailers [27]. The study found that peer-induced fairness concerns are more salient than distributional ones. Nie and Du considered a two-level supply chain consisting of one supplier and two retailers, one with distributional fairness concerns and the other with distributional and peer-induced fairness concerns, and found that the quantity discount contract combined with fixed transfer payments can effectively coordinate the supply chain [28]. Zhang et al. considered the impact of consumer environmental awareness (CEA), retailer's fairness concerns, and government subsidies on the two echelon supply chain with one manufacturer and one retailer [29]. Overall fairness can provide a more concise, more powerful, and more accurate description for people's experience than fairness of multi-dimensions. Ultimately, the behavioral decisions often rely on overall fairness perception. Ambrose and Schminke pointed out that overall fairness can mediate the relationship between a specific fairness dimension and employee attitudes [30]. Barclay and Kiefer studied whether overall fairness was related to positive and negative emotions, and whether these two emotions can mediate the relationship between overall fairness and behavioral outcomes, and found that positive emotions continually regulated the relationship between overall fairness and proximity behavior, while negative emotions continuously regulated the relationship between overall fairness and avoidance behavior [31]. Aryee et al. examined two ways in which overall fairness affects job performance. The results showed that demand satisfaction regulates the relationship between overall fairness and intrinsic motivation and the relationship between overall fairness and trust in the organization. They also found that intrinsic motivation regulates the impact of demand satisfaction and trust on job performance in the organization [32].

By combing the relevant literature, we can see that: (1) The research on strategic alliances gradually develops in two directions: one is to explore the formation of new forms of strategic alliances; the other is to conduct more in-depth research on alliance management from the perspective of alliance combination and alliance network by combining with practice. There are few studies on inventory transshipment strategic alliances. (2) Previous research on inventory transshipment focus on the optimal ordering decision when inventory transshipment is adopted and how the transshipment profits are distributed, but the research on the inventory transshipment is still rare from the perspective of strategic alliances. (3) Some papers studied the influence of fairness on decision makers from various dimensions of fairness, while others focused on the perspective of overall fairness. Overall fairness can provide a more concise, more powerful, and more accurate description for people's experience than fairness of multi-dimensions. In view of this, this paper introduces fairness concerns from the perspective of overall fairness, and studies the impacts of fairness concerns on the formation of 
inventory transshipment strategy alliance through the impacts of fairness concerns on the two retailers' ordering decisions and profits, and these make up for the shortcomings in existing research.

\section{Problem Assumptions and Benchmark Model}

This paper considers the system consisting of two retailers at distinct locations indexed by $i, j=1,2(i \neq j)$ under uncertain market demand.

Suppose that the demands of two retailers are $D_{i}, D_{j}$ respectively, and are independent of each other, and the two retailers do not know the level of market demand that will be realized at the two locations, but the joint distribution $\left(D_{1}, D_{2}\right)$ in the face of market demand is known, and the joint distribution is second-order differentiable. In the case of single cycle and without replenishment, in order to improve their own profits and service levels to customers, the two retailers face stochastic demand and carry out an inventory transshipment strategy. The retailers must order their initial inventory before the demand is realized and the order quantities are respectively $Q_{i}, Q_{j}$. The total quantity is $Q$. After demand realization, the retailers transship the excess inventory to the other. The amount of transshipment of the retailer $i$ is $T_{i j}=\min \left(\left(Q_{i}-D_{i}\right)^{+},\left(D_{j}-Q_{j}\right)^{+}\right)$. The actual sales volume of the retailer $i$ after the transshipment is $R_{i}=\min \left(D_{i}, Q_{i}\right)+T_{j i}$. The unsold inventory is $V_{i}=\left(Q_{i}-D_{i}-T_{i j}\right)^{+}$, and the unmet demand is $Z_{i}=\left(D_{i}-Q_{i}-T_{j i}\right)^{+}$.

The retailer $i$ purchases inventory at a fixed unit $\operatorname{cost} c_{i}=c$, and obtains profit $r_{i}>c$ for every unit sold. The unit residual value of the remaining inventory is $s_{i}<c$, and the unit penalty cost of unmet demand is $p_{i} \geq 0$. We define $v_{i}=r_{i}+p_{i}$ as the marginal value of additional retail sales at location $i$.

We assume that the transshipment prices are independent of the demand realizations and inventory levels of the two retailers, and the transshipment prices does not change with the magnitude of excess inventory at one location or the size of shortage at the other. $c_{i j}$ is the transshipment price charged by retailer $i$ for each unit transshipped to the retailer $j$, and $\tau_{i j}$ is the corresponding transshipment cost. Here we assume that the transshipment price is determined by the retailer that implements the transshipment. The unit profit is $c_{i j}-\tau_{i j}$ when transshipping the product. The transshipment price $s_{i}+\tau_{i j} \leq c_{i j} \leq v_{j}$ ensures that the transshipment conducted by the retailers is beneficial to themselves. Meanwhile, it is no more expensive to order a unit for retailer $j$ than it is to order a unit for the other retailer $i$ and then immediately transship it to retailer $j$, the triangle inequality $c_{i j} \geq c_{j i}-\tau_{j i}$ must hold. By adopting the assumption of Tagaras $s_{i}<s_{j}+\tau_{j i}, v_{i}<v_{j}+\tau_{j i}$ the implementation of complete inventory pooling can be ensured, that is, when one retailer has excess inventory while another retailer is out of stock, the transshipment level is the minimum of excess inventory and unmet demand [33].

Then we use Figure 1 to describe the situations of the demand of two retailers utilizing transshipment.

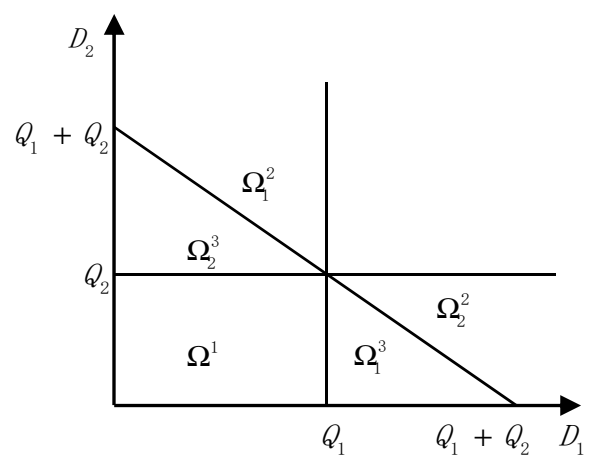

Figure 1. Situations of the Demand of Two Retailers with Transshipment. 
The area $\Omega^{1}+\Omega_{i}^{2}+\Omega_{j}^{3}$ in Figure 1 shows the situation where retailer $i$ has excess inventory. The area $\Omega^{1}$ shows the situation where both the two retailers have excess inventory and don't need to transship. The area $\Omega_{i}^{2}$ shows the situation when retailer $i$ implements transshipment: retailer $i$ has the excess inventory while retailer $j$ is out of stock, so retailer $i$ fully provides the remaining inventory for retailer $j$. The area $\Omega_{i}^{3}$ shows the situation that retailer $i$ accepts transshipment: retailer $i$ is out of stock while retailer $j$ has the excess inventory, so retailer $i$ accepts the part of remaining inventory provided by retailer $j$. Table 1 below gives a detailed description of the demand, the corresponding probability function and the associated transshipment in different situations.

Table 1. Situations of the Demand and Associated Probability Functions.

\begin{tabular}{cccc}
\hline Situations & Description & Probability & Transshipment \\
\hline$\Omega^{1}+\Omega_{i}^{2}+\Omega_{j}^{3}$ & $D_{i} \leq Q_{i}$ & $\alpha_{i}$ & $T_{j i}=0$ \\
$\Omega_{i}^{2}$ & $Q_{i}+Q_{j}-D_{j}<D_{i} \leq Q_{i}$ & $\beta_{i}$ & $T_{j i}=0, T_{i j}=Q_{i}-D_{i}$ \\
$\Omega_{i}^{3}$ & $Q_{i}<D_{i} \leq Q_{i}+Q_{j}-D_{j}$ & $\gamma_{i}$ & $T_{i j}=0, T_{j i}=D_{i}-Q_{i}$ \\
\hline
\end{tabular}

The profit of retailer $i$ with no fairness concerns is:

$$
\pi_{i}=E\left(r_{i} R_{i}+\left(c_{i j}-\tau_{i j}\right) T_{i j}-c_{j i} T_{j i}+s_{i} V_{i}-p_{i} Z_{i}\right)-c Q_{i}, i, j=1,2
$$

The conditions characterizing the optimal inventory order are:

$$
\alpha_{i}-\frac{c_{i j}-\tau_{i j}-s_{i}}{v_{i}-s_{i}} \beta_{i}+\frac{v_{i}-c_{j i}}{v_{i}-s_{i}} \gamma_{i}=\frac{v_{i}-c}{v_{i}-s_{i}}
$$

for $i, j=1,2$. In the scenario of completely rationality denoted by $\mathrm{NN}$, as long as the transshipment price satisfies $c_{i j}^{N N} \in\left[s_{i}+\tau_{i j}, v_{j}\right], i, j=1,2$, there exists a unique Nash equilibrium for the order quantities of the two retailers [4].

\section{Fairness Concerns and Their Impacts on Order Quantities and Profits}

Due to the heterogeneity of retailer preference for fairness, retailers can be fairness neutral $(\mathrm{N})$ or fairness concerned (F). There are two scenarios for two retailers with transshipment: asymmetric fairness concerns denoted by NF, that is, one retailer is fairness neutral and the other concerns fairness, and symmetric fairness concerns denoted by $\mathrm{FF}$, that is, both retailers concern fairness.

Following the Cui et al. model [26], when retailer $i$ concerns fairness [12,34], the utility function of retailer is as follows:

$$
U_{i}=\pi_{i}+f_{i}, i, j=1,2
$$

Where $f_{i}$ is the organizational justice utility caused by the retailer's fairness concerns, which reflects the retailer's sense of organizational justice in the strategic alliance. When $f_{i} \geq 0$, the retailer feeling fairly treated by the partner in the strategic alliance is willing to cooperate; when $f_{i}<0$, the retailer feeling unfairly treated is not willing to cooperate.

By introducing reference point dependency to describe the retailer's fairness concerns utility function, we focus on overall fairness and adopt a simplified fairness utility function. Here, the counterpart profit is used as a reference point. According to Kahneman and Tversky [35], the sensitivity degree of economic entities to profits and losses is inconsistent, that is, the inverse $\mathrm{S}$-shaped curve. For the sake of simple calculations, it is assumed that the decision-makers are similarly sensitive to the same profits and losses, that is, linear. We introduce the fairness parameter $\lambda_{i}$, and $\lambda_{i} \geq 0$. Therefore, the utility function of the organizational justice is $f_{i}=-\lambda_{i}\left(\pi_{j}-\pi_{i}\right)$. For the convenience of model analysis, we denote $\hat{\lambda}_{i} \equiv \lambda_{i} /\left(1+\lambda_{i}\right)$. It is easy to know that $\hat{\lambda}_{i}$ is increasing in $\lambda_{i}$, and $\hat{\lambda}_{i} \in[0,1)$. If $\lambda_{i}=0$, then $\hat{\lambda}_{i}=0$, and the retailer is fairness neutral. If $\lambda_{i} \rightarrow+\infty$, then $\hat{\lambda}_{i} \rightarrow 1$, and the retailer concerns fairness extremely. Further analysis is performed on the basis of the above 
transformation. Equating the first-order condition of retailer to zero, we can get the equations for $i, j=1,2$ :

$$
\alpha_{i}-\frac{c_{i j}-s_{i}-\tau_{i j}-\hat{\lambda}_{i}\left(v_{j}-c_{i j}\right)}{v_{i}-s_{i}} \beta_{i}+\frac{v_{i}-c_{j i}-\hat{\lambda}_{i}\left(c_{j i}-s_{j}-\tau_{j i}\right)}{v_{i}-s_{i}} \gamma_{i}=\frac{v_{i}-c}{v_{i}-s_{i}}
$$

\subsection{The Order Quantity}

This section analyses the retailer's order quantities under asymmetric and symmetric fairness concerns.

Under asymmetric fairness concerns, one retailer is fairness neutral while the other retailer is fairness concerned, and the conclusions of the scenario NF and FN are similar. Therefore, we only discuss one scenario. Here we consider the scenario NF. In the scenario NF, retailer 1(he) is fairness neutral while retailer 2(she) is fairness concerns, introducing the fairness parameter $\lambda_{2}$ for retailer 2 .

Lemma 1. In the scenario $N F$, let $c_{12}^{N F} \in\left[s_{1}+\tau_{12}, \frac{v_{2}+\hat{\lambda}_{2}\left(s_{1}+\tau_{12}\right)}{1+\hat{\lambda}_{2}}\right], c_{21}^{N F} \in\left[\frac{\hat{\lambda}_{2} v_{1}+\left(s_{2}+\tau_{21}\right)}{1+\hat{\lambda}_{2}}, v_{1}\right]$, then there exists a unique Nash equilibrium. The initial order quantity $\left(Q_{1}^{N F}, Q_{2}^{N F}\right)$ is obtained by the Equations (2) and (4). (The proof of Lemma 1 is similar to Rudi [5])

Under the symmetric fairness concerns, both retailers are concerned about fairness, introducing the parameters $\lambda_{i}^{\prime}, \lambda_{j}^{\prime}, i, j=1,2$, and $\lambda_{i}^{\prime}, \lambda_{j}^{\prime} \geq 0$.

Lemma 2. In the scenario $F F$, let $c_{i j}^{F F} \in\left[\frac{\left(s_{i}+\tau_{i j}\right)+\hat{\lambda}_{i}^{\prime} v_{j}}{1+\hat{\lambda}_{i}^{\prime}}, \frac{v_{j}+\hat{\lambda}_{j}^{\prime}\left(s_{i}+\tau_{i j}\right)}{1+\hat{\lambda}_{j}^{\prime}}\right], i, j=1,2$, then there exists a unique Nash equilibrium. The initial order quantity $\left(Q_{1}^{F F}, Q_{2}^{F F}\right)$ is obtained by the Equations (4). (The proof of Lemma 2 is similar to Rudi [5])

\subsection{The Impacts of Fairness Concerns on Order Quantities and Profits}

This section focuses on the impacts of the fairness parameters on the order quantities and profits of two retailers under asymmetric and symmetric fairness concerns. We find the solutions separately using the implicit function theorem. It can be seen that the impacts of the fairness parameters on the order quantities and profits is closely related to the total marginal average profits for the transshipment of retailer $i \eta_{i}=\left(v_{i}-c_{j i}\right) \beta_{j}-\left(c_{i j}-s_{i}-\tau_{i j}\right) \gamma_{j}, i, j=1,2$. The formula $\eta_{i}$ reflects the propensity of retailer $i$ to accept transshipment or implement transshipment. When $\eta_{i}=0$, the retailer has no difference in accepting transshipment and implementing transshipment; when $\eta_{i}>0$, the retailer tend to accept transshipment; when $\eta_{i}<0$, the retailer tend to implement transshipment. Where $\left(v_{i}-c_{j i}\right) \beta_{j}$ represents the marginal average profits when retailer $i$ accepts transshipment; and $\left(c_{i j}-s_{i}-\tau_{i j}\right) \gamma_{j}$ represents the marginal average profits from the implementation of transshipment of retailer $i$. As can be seen in conjunction with Table 1, whether the retailer $i$ is inclined to accept transshipment or implement transshipment, the amount of transshipment is controlled by retailer $j$.

\subsubsection{Asymmetric Fairness Concern}

The following is a study of the impacts of retailers' fairness concerns on the order quantities and profits of retailers under asymmetric fairness concern (Scenario NF).

Proposition 1. In the scenario NF: when $\eta_{1}=0$, the order quantities of two retailers does not change with $\lambda_{2}$; when $\eta_{1}>0$, the more retailer 2 pays attention to fairness, the larger the order quantity of retailer 1 , the smaller the order quantity of retailer 2 , and the smaller the total order quantity; when $\eta_{1}<0$, the more retailer 2 pays attention to fairness, the smaller the order quantity of retailer 1, and the larger the order quantity of retailer 2 , the larger the total order quantity. 
Proposition 1 indicates that when retailer 1 has no difference in accepting and implementing transshipment, although retailer 2 concerns fairness and controls the amount of transshipment, the order quantity of retailer 2 will not change with fairness, and the order quantity of retailer 1 will not change as well. When retailer 1 tend to accept transshipment, retailer 2 concerning fairness will reduce the transshipment level to retailer 1 by reducing her initial order quantity while retailer 1 has to increase his order quantity to meet market demand. When retailer 1 tends to implement transshipment, retailer 2 concerning fairness will reduce the transshipment quantity from retailer 1 by increasing her initial order quantity while retailer 1 reduces his order quantity accordingly.

Proposition 2. In the scenario NF, the more retailer 2 is concerned with fairness, the smaller the profits of retailer 1, the smaller the profits of retailer 2 in the condition $C_{1}^{N F}$ and the greater the profits of retailer 2 in the condition $C_{2}^{N F}$.

Proposition 2 shows that in the scenario NF, profits are affected by $\lambda_{2}$. The retailer's profit consists of two parts, one part derived from direct sales and the other from the transshipment. Due to retailer 2 being concerned about fairness, retailer 2 controls the transshipment quantity to reduce the indirect benefits of retailer 1 through transshipment, resulting in a decline in the total profit of retailer 1 . The behavior of retailer 2 may increase or decrease her own profits.

Theorem 1. In the scenario NF: the profits of the retailer with no fairness is always less than his corresponding profits in the scenario $N N$; the profits of the retailer with fairness concerns in the condition $C_{1}^{N F}$ is less than her corresponding profits in the scenario NN while being greater than her corresponding profits in the scenario NN in the condition $C_{2}^{N F}$.

Combined with conditions $C_{1}^{N F}$ and $C_{2}^{N F}$, it can be seen from Theorem 1 that, compared with the scenario of complete rationality, the retailer's profits under asymmetric fairness concerns have the following two cases: when both retailers tend to accept transshipment (implement transshipment), the profit of the retailer with no fairness are hurt, and the retailer with fairness concerns may benefit or suffer from her own fairness concerns; when one retailer tends to implement transshipment and the other tends to accept transshipment, the profits of the two retailers are both hurt.

\subsubsection{Symmetric Fairness Concerns}

This section focuses on the impacts of retailers' fairness concerns on their order quantities and profits under symmetric fairness concerns.

Proposition 3. In the scenario FF: when two retailers have no difference in accepting and implementing transshipment, the retailers' order quantities does not vary with the fairness parameters of two retailers; when both retailers tend to accept transshipment (implement transshipment), the tendency for the order quantity of retailer 1 (retailer 2) with increased $\lambda_{i}^{\prime}$ is opposite to that with increased $\lambda_{j}^{\prime}$; when one retailer tends to implement transshipment while the other tends to accept transshipment, the tendency for the order quantity of retailer 1 (retailer 2) with increased $\lambda_{i}^{\prime}$ is the same as that with increased $\lambda_{j}^{\prime}$.

Proposition 3 shows that the order quantities are affected by $\lambda_{i}^{\prime}, \lambda_{j}^{\prime}$ at the same time under symmetric fairness concerns. When both retailers are concerned about fairness, the impacts of the fairness parameters on the order quantity are superposed, and the two effects reinforce each other or cancel each other out. Specifically, when one retailer tends to implement transshipment while the other tends to accept transshipment, the two effects reinforce each other; when both retailers tend to accept transshipment (implement transshipment), the two effects cancel each other out. 
Proposition 4. In the scenario FF: in the condition $C_{5} \cup C_{6}\left(C_{9} \cup C_{10}\right)$, the tendency for the profit of retailer 1 (retailer 2) with increased $\lambda_{i}^{\prime}$ is opposite to that with increased $\lambda_{j}^{\prime}$; in the condition $C_{3} \cup C_{4}\left(C_{7} \cup C_{8}\right)$, the tendency for the profit of retailer 1 (retailer 2) with increased $\lambda_{i}^{\prime}$ is the same as that with increased $\lambda_{j}^{\prime}$.

Proposition 4 shows that changes in profits are affected by $\lambda_{i}^{\prime}, \lambda_{j}^{\prime}$ at the same time. When two retailers are concerned about fairness, the impacts of the fairness parameters on profits are superposed, and the two effects reinforce each other or cancel each other out. Specifically, when the two effects reinforce each other, the profit of retailer 1 (retailer 2) simultaneously increases or decreases; when the two effects cancel each other out, the profit of retailer 1 (retailer 2) increases with one fairness concerns parameter while decreases with the other fairness parameter.

Theorem 2. In the scenario FF: in the condition $C_{5} \cup C_{6}\left(C_{9} \cup C_{10}\right)$, two retailers may benefit or suffer from the two fairness parameters compared with the scenario $N N$; in the condition $C_{4}\left(C_{8}\right)$, the profit of retailer 1 (retailer 2) is greater than the corresponding profits in the scenario $N N$; in the condition $C_{3}\left(C_{7}\right)$, the profit of the retailer 1 (the retailer 2 ) is less than the corresponding profits in the scenario NN.

Theorem 3. In the scenario FF: in the condition $C_{2}^{F F}\left(C_{4}^{F F}\right)$, the profit of retailer 1(retailer 2) is greater than the corresponding profits in the scenario NF; in the condition $C_{1}^{F F}\left(C_{3}^{F F}\right)$, the profit of the retailer 1 (the retailer 2$)$ is less than the corresponding profits in the scenario NF.

It can be seen from Theorems 2 and 3 that under symmetric fairness concerns, the profits of two retailers may be greater or less than their corresponding profits in the scenario of completely rationality, and may be greater or less than their corresponding profits under asymmetric fairness concerns. Combined with the condition $C_{m}$ and $C_{n}^{F F}$, it can be seen that, under symmetric fairness concerns: when two retailers are inclined to accept transshipment (implement transshipment), the profits of the two retailers may be greater or less than their corresponding profits in the scenario of completely rationality, and may be greater or less than their corresponding profits under asymmetric fairness concerns; when a retailer tends to implement transshipment while another retailer tends to accept transshipment, the profits of both retailers are less than their corresponding profits in the scenario of completely rationality, and are also less than their corresponding profits under asymmetric fairness concerns. The gap between the profits of both retailers under symmetric fairness concerns and the corresponding profits in the scenario of completely rationality is greater.

Through Propositions 1 and 3, it can be seen that: (1) The tendency for the order quantity of retailer 1 with increased fairness is opposite to that of retailer 2 with increased fairness, because the two retailers' order quantities are alternatives when satisfying customer demand. (2) The tendency for the order quantity of the fairness-concerned retailer with increased fairness is the same as the total order quantity of with increased fairness, indicating that the retailer with fairness concerns is strongly influenced by her own fairness concerns when ordering while the retailer with no fairness is less affected.

Through Propositions 2 and 4, it can be seen that: (1) under asymmetric fairness concerns, the more the retailer with fairness concerns are concerned about fairness the smaller the profit of retailer with no fairness; (2) under symmetric fairness concerns, the impacts of the two fairness parameters on profits are superimposed, and these two effects reinforce each other or cancel each other out.

It can be seen from Theorems 1-3 that the two retailers with transshipment should focus on the profit of direct sales of products. Concerns over the profit of indirect profits derived from transshipment will damage their own profits. This is in line with corporate practice in the real world.

\section{Numerical Analysis}

Since the mathematical model can't clearly give the retailer's order quantities and profits, we use numerical analysis to study the condition for the formation of a strategic alliance under the asymmetric and symmetric fairness concerns, take the total profits as the performance of the strategic alliance, 
and compare the performance of the strategic alliance in two scenarios with a scenario of complete rationality. The basis for judging the formation of a strategic alliance, that is, the implementation of the inventory transshipment strategy, is: the utility of the retailer $f_{i} \geq 0.000$ when the retailer is concerned about fairness, the profit of the retailer $\pi_{i}>\pi_{i}^{N}$ when the retailer is fairness neutral. Where $\pi_{i}^{N}$ is the corresponding profits when the retailer doesn't adopt the inventory transshipment strategy, $i=1,2$.

Assume that the demand of retailer 1 and retailer 2 obey uniform distribution $D_{i} \sim U[0,100]$, $i=1$, 2. Let unit retail price $r_{1}=r_{2}=10$, salvage value $s_{1}=s_{2}=4$, penalty for lost sales $p_{1}=p_{2}=2$, purchase $\operatorname{cost} c=5$, unit transshipment $\operatorname{cost} \tau_{12}=\tau_{21}=0.500$, the range of the transshipment price is $4.500 \leq c_{12}, c_{21} \leq 12$.

When two retailers do not form a strategic alliance, the retailer's order quantity is $Q_{i}^{N}=87.500$, and the retailer's profits is $\pi_{i}^{N}=181.250, i=1,2$. The expression of the probability function is as follows:

$$
\begin{aligned}
& \alpha_{i}\left(Q_{i}\right)= \begin{cases}\frac{1}{100} Q_{i} & \text { if } 0<Q_{i} \leq 100 \\
1 & \text { others }\end{cases} \\
& \beta_{i}\left(Q_{i}, Q_{j}\right)= \begin{cases}\frac{1}{10000}\left(100 Q_{i}-Q_{i} Q_{j}-\frac{1}{2} Q_{i}^{2}\right) & \text { if } 0<Q_{j} \leq 100-Q_{i} \\
\frac{1}{20000}\left(100-Q_{j}\right)^{2} & \text { if } 100-Q_{i}<Q_{j} \leq 100 \\
0 & \text { others }\end{cases} \\
& \gamma_{i}\left(Q_{i}, Q_{j}\right)= \begin{cases}\frac{1}{20000} Q_{j}^{2} & \text { if } 0<Q_{j} \leq 100-Q_{i} \\
\frac{1}{20000}\left(100-Q_{i}\right)\left(2 Q_{j}+Q_{i}-100\right) & \text { if } 100-Q_{i}<Q_{j} \leq 100 \\
\frac{1}{20000}\left[\left(100-Q_{i}\right)\left(2 Q_{j}+Q_{i}-100\right)-\left(Q_{j}-100\right)^{2}\right] & \text { if } 100<Q_{j} \leq 200-Q_{i} \\
0 & \text { others }\end{cases}
\end{aligned}
$$

Table 2 shows the sensitivity of the order quantities and profits to the fairness parameter in the scenario NF. The order quantity of retailer 1 is decreasing in $\hat{\lambda}_{2}$, the order quantity of retailer 2 is increasing in $\hat{\lambda}_{2}$, and the total order quantity is also increasing in $\hat{\lambda}_{2}$. The profit of retailer 1 is decreasing in $\hat{\lambda}_{2}$, the organizational justice utility of retailer 2 is increasing in $\hat{\lambda}_{2}$, and the total profit is decreasing in $\hat{\lambda}_{2}$. The retailer with no fairness concerns tends to the lower fairness parameter and the retailer with fairness concerns tends to the higher fairness parameter.

Table 2. Impacts of Fairness Parameters on Order Quantities and Profits in the Scenario NF.

\begin{tabular}{cccccccccc}
\hline$c_{12}$ & $c_{21}$ & $\hat{\lambda}_{2}$ & $Q_{1}$ & $Q_{2}$ & $Q$ & $\pi_{1}$ & $\pi_{2}$ & $\pi$ & $f_{2}$ \\
\hline 8 & 8 & 0.000 & 81.576 & 81.576 & 163.153 & 215.089 & 215.089 & 430.177 & 0.000 \\
8 & 8 & 0.200 & 81.222 & 82.994 & 164.570 & 214.455 & 215.219 & 429.675 & 0.192 \\
8 & 8 & 0.400 & 80.931 & 84.177 & 165.753 & 213.972 & 215.256 & 429.228 & 0.856 \\
8 & 8 & 0.600 & 80.689 & 85.177 & 166.753 & 213.596 & 215.235 & 428.831 & 2.460 \\
8 & 8 & 0.800 & 80.484 & 86.031 & 167.608 & 213.298 & 215.181 & 428.479 & 7.530 \\
\hline
\end{tabular}

Table 3 shows the sensitivity of the order quantities and profits of two retailers to the transshipment price in the scenario NF. As can be seen from Table 3, when $\hat{\lambda}_{2}=0.400, c_{21} \in\{7,8,9\}$, the total order quantity is increasing in and the total profits is decreasing in $c_{i j}$. The organizational justice utility of retailer 2 is decreasing in $c_{12}$ and increasing in $c_{21}$. The retailer with fairness concerns tends to lower the transshipment price of the other partner, and raise her own transshipment prices.

It can be seen from the above analysis that under asymmetric fairness concerns, the profits of retailer 1 are always greater than the profits when no strategic alliance is formed. When the transshipment price of retailer 1 is no more than the transshipment price of retailer 2, the organizational justice utility of retailer 2 is always no less than 0.000 , and the inventory transshipment strategy alliance can be formed. When the transshipment price of retailer 1 is more than the transshipment price of retailer 2 , the organizational justice utility of retailer 2 may be more than or less than 0.000 , and 
retailer 1 may pay retailer 2 a certain fee $\Delta$ in order to form a strategic alliance, and $\Delta$ needs to satisfy the condition $\frac{\pi_{1}-\pi_{2}}{2} \leq \Delta \leq \pi_{1}-181.250$. Compared with the scenario of complete rationality, the strategic alliance under asymmetric fairness concerns has a larger total order quantity, and less smaller total profits and alliance performance.

Table 3. Impacts of Transshipment Prices on Order Quantities and Profits in the Scenario NF.

\begin{tabular}{cccccccccc}
\hline$c_{12}$ & $c_{21}$ & $\hat{\lambda}_{2}$ & $Q_{1}$ & $Q_{2}$ & $Q$ & $\pi_{1}$ & $\pi_{2}$ & $\pi$ & $f_{2}$ \\
\hline 7 & 7 & 0.400 & 78.667 & 81.102 & 159.769 & 215.424 & 216.125 & 431.549 & 0.467 \\
8 & 7 & 0.400 & 78.033 & 84.011 & 162.044 & 215.634 & 215.031 & 430.665 & -0.402 \\
9 & 7 & 0.400 & 77.494 & 86.197 & 163.691 & 215.682 & 214.244 & 429.927 & -0.959 \\
7 & 8 & 0.400 & 81.367 & 81.124 & 162.490 & 213.960 & 216.513 & 430.473 & 1.702 \\
8 & 8 & 0.400 & 80.931 & 84.177 & 165.108 & 213.972 & 215.256 & 429.228 & 0.856 \\
9 & 8 & 0.400 & 80.558 & 86.449 & 167.007 & 213.859 & 214.346 & 428.204 & 0.325 \\
7 & 9 & 0.400 & 83.578 & 81.028 & 164.606 & 212.862 & 216.620 & 429.482 & 2.505 \\
8 & 9 & 0.400 & 83.294 & 84.205 & 167.499 & 212.728 & 215.196 & 427.923 & 1.645 \\
9 & 9 & 0.400 & 83.044 & 86.554 & 169.598 & 212.496 & 214.160 & 426.655 & 1.109 \\
\hline
\end{tabular}

Table 4 shows the sensitivity analysis of the order quantity and profits to the fairness parameters in scenario FF. It is generally assumed that the transshipment price is the same, $c_{12}=c_{21}=8$. It can be seen that whether the fairness parameters are the same or not, the total order quantity is respectively increasing in $\hat{\lambda}_{1}^{\prime}, \hat{\lambda}_{2}^{\prime}$, and the total profits are decreasing in $\hat{\lambda}_{1}^{\prime}, \hat{\lambda}_{2}^{\prime}$.

Table 4. Impacts of Fairness parameters on Order Quantities and Profits in the Scenario FF.

\begin{tabular}{ccccccccc}
\hline$c_{12}$ & $c_{21}$ & $\hat{\lambda}_{1}^{\prime}, \hat{\lambda}_{2}^{\prime}$ & $Q_{1}$ & $Q_{2}$ & $Q$ & $\pi_{1}, \pi_{2}$ & $\pi$ & $f_{1}, f_{2}$ \\
\hline 8 & 8 & 0.000 & 81.576 & 81.576 & 163.153 & 215.089 & 430.177 & 0.000 \\
8 & 8 & 0.200 & 82.724 & 82.724 & 165.448 & 214.526 & 429.052 & 0.000 \\
8 & 8 & 0.400 & 83.830 & 83.830 & 167.660 & 213.915 & 427.830 & 0.000 \\
8 & 8 & 0.600 & 84.881 & 84.881 & 169.761 & 213.276 & 426.552 & 0.000 \\
8 & 8 & 0.800 & 85.867 & 85.867 & 171.734 & 212.627 & 425.255 & 0.000 \\
\hline
\end{tabular}

Table 5 shows the sensitivity of the order quantity and profits to the transshipment price in the scenario FF. When $c_{12}, c_{21} \in\{7,8,9\}$, the total order quantity is increasing in $c_{i j}$ and the total profit is decreasing in $c_{i j}$. The organizational justice utility of retailer $i$ is increasing in $c_{i j}$, the organizational justice utility of retailer $j$ is decreasing in $c_{i j}$. Retailers tend to lower the transshipment price of the other side, and raise their own transshipment price.

Table 5. Influence of Transshipment Prices on Order Quantities and Profits in the Scenario FF.

\begin{tabular}{ccccccccccc}
\hline$c_{12}$ & $c_{21}$ & $\hat{\lambda}_{1}^{\prime}, \hat{\lambda}_{2}^{\prime}$ & $Q_{1}$ & $Q_{2}$ & $Q$ & $\pi_{1}$ & $\pi_{2}$ & $\pi$ & $f_{1}$ & $f_{2}$ \\
\hline 7 & 7 & 0.400 & 80.775 & 80.775 & 161.550 & 215.435 & 215.435 & 430.871 & 0.000 & 0.000 \\
8 & 7 & 0.400 & 80.636 & 83.798 & 164.434 & 215.566 & 214.002 & 429.567 & 1.042 & -1.043 \\
9 & 7 & 0.400 & 80.435 & 86.086 & 166.521 & 215.536 & 212.940 & 428.476 & 1.731 & -1.731 \\
7 & 8 & 0.400 & 83.798 & 80.636 & 164.434 & 214.002 & 215.566 & 429.567 & -1.043 & 1.042 \\
8 & 8 & 0.400 & 83.830 & 83.830 & 167.660 & 213.915 & 213.915 & 427.830 & 0.000 & 0.000 \\
9 & 8 & 0.400 & 83.772 & 86.224 & 169.996 & 213.707 & 212.695 & 426.403 & 0.675 & -0.674 \\
7 & 9 & 0.400 & 86.086 & 80.435 & 166.521 & 212.940 & 215.536 & 428.476 & -1.731 & 1.731 \\
8 & 9 & 0.400 & 86.224 & 83.772 & 169.996 & 212.695 & 213.707 & 426.403 & -0.674 & 0.675 \\
9 & 9 & 0.400 & 86.253 & 86.253 & 172.506 & 212.361 & 212.361 & 424.723 & 0.000 & 0.000 \\
\hline
\end{tabular}

It can be seen from the above analysis that under symmetric fairness concerns, when two retailers are completely symmetric, the organizational justice utility of both retailers is 0.000 . It is believed that the sense of organizational justice can help form a strategic alliance. Compared with the scenario of 
complete rationality, the strategic alliance under symmetric fairness concerns has a larger total order quantity, smaller total profits and alliance performance.

From the equilibrium order quantities of retailers under all the above different conditions, it is found that the total marginal average profits of two retailers are both negative, i.e., both retailers tend to implement transshipment when making order decisions. This can be explained by the fact that, under fairness concerns, when retailers are making an ordering decision under uncertain demand, retailers tend to implement transshipment and gain more initiative by controlling the quantity of the transshipment.

\section{Conclusions}

Sustainable operations management has been obtaining more and more attention, especially regarding how best to build resilience into supply chain under demand uncertainty. Demand uncertainty usually results in supply-demand mismatch. Retailers located in different regions adopt inventory transshipment strategies to form strategic alliances in a farsighted sense, correcting mismatches between uncertain demands and their available inventories, improving supply chain operational efficiency and realizing sustainable operations.

Fairness concerns are introduced to study the formation of the inventory transshipment strategic alliance through their impacts on two retailers' ordering decisions and profits. The paper studied the ordering decision of two retailers under asymmetric and symmetric fairness concerns. The conditions for Nash equilibrium solution about the order quantities of two retailers were also given. We investigated the impacts of retailer fairness concerns on his or her order quantities and profits by the implicit function theorem, and found that under fairness concerns: (1) The order quantity of the fairness-concerned retailer is strongly influenced by her own fairness concerns while the order quantity of the other retailer is less affected. When retailers with transshipment are making ordering decisions under uncertain demand, retailers tend to implement transshipment and gain more initiative by controlling the quantity of transshipment. (2) The two retailers involved in transshipment should focus on the profit of direct sales of products. Concerns over the profit of indirect profits derived from transshipment will damage their total profits.

Based on the theoretical analysis and numerical examples, this paper investigated the formation of strategic alliance under asymmetric and symmetric fairness concerns. The results are as follows: (1) Under asymmetric fairness concerns, when the transshipment price of the retailer with no fairness concerns is no more than the transshipment price of the retailer with fairness concerns, an inventory transshipment strategy alliance can be formed. Otherwise the retailer with no fairness concerns may need to pay the retailer with fairness concerns certain fees in order to form a strategic alliance. (2) Under symmetric fairness concerns, a strategic alliance can be formed when the two retailers are completely symmetric.

However, this paper still has the following limitations. First, when facing a stockout, the paper only considers the case of the two retailers with transshipment behavior, without considering consumer switching behavior. In fact, when one retailer faces a stockout, some customers are likely to switch to the other retailer. Second, this paper does not consider the scenario of multiple retailers utilizing transshipment. In the same region of the market, there are often multiple retailers. These issues remain for further study.

Author Contributions: X.Y. and S.W. conceived the paper. X.Y., S.W., X.Z. discussed the optimization method. X.Y. wrote the paper. All authors read and discussed the final manuscript.

Acknowledgments: This research was funded by the National Nature Science Foundation of China (Grant Numbers 71501094), the MOE (Ministry of Education in China) Project of Humanities and Social Sciences (Grant Numbers 16YJC630116), and “Shanxi'1331 Project' Key Innovation Research Team".

Conflicts of Interest: The authors declare no conflict of interest. 


\section{Appendix A}

\section{Appendix A.1 Proof of Lemma 1}

Under asymmetric fairness concerns, the initial order quantity $\left(Q_{1}^{N F}, Q_{2}^{N F}\right)$ is obtained by the Equations (2) and (4).

To establish the existence of a unique Nash equilibrium, it is sufficient to show that the reaction functions are monotonic, and the absolute value of the slope is less than 1 (see Rudi [5]).

The implicit function equations can be obtained from Equations (2) and (4):

$$
\begin{gathered}
F\left(\lambda_{j}, Q_{i}, Q_{j}\right)=\left(v_{i}-s_{i}\right) \alpha_{i}-\left(c_{i j}-s_{i}-\tau_{i j}\right) \beta_{i}+\left(v_{i}-c_{j i}\right) \gamma_{i}-\left(v_{i}-c\right) \\
\begin{aligned}
G\left(\lambda_{j}, Q_{i}, Q_{j}\right) \quad= & \left(1+\lambda_{j}\right)\left(v_{j}-s_{j}\right) \alpha_{j}-\left[\left(1+\lambda_{j}\right)\left(c_{j i}-s_{j}-\tau_{j i}\right)-\lambda_{j}\left(v_{i}-c_{j i}\right)\right] \beta_{j} \\
& +\left[\left(1+\lambda_{j}\right)\left(v_{j}-c_{i j}\right)-\lambda_{j}\left(c_{i j}-s_{i}-\tau_{i j}\right)\right] \gamma_{j}-\left(1+\lambda_{j}\right)\left(v_{j}-c\right)
\end{aligned}
\end{gathered}
$$

Since the joint probability distribution of demand is continuously differentiable, then $\alpha_{i}\left(Q_{i}\right)$, $\beta_{i}\left(Q_{i}, Q_{j}\right)$ and $\gamma_{i}\left(Q_{i}, Q_{j}\right)$ are differentiable for $Q_{i}$ and $Q_{j} . a_{i}=\mathrm{f}_{D_{i}}\left(Q_{i}\right)$ is the probability density function. The following is the corresponding marginal probability density function:

$$
\begin{aligned}
& b_{i j}^{1}=\operatorname{pr}\left(D_{i}<Q_{i}\right) \mathrm{f}_{D_{i}+D_{j} \mid\left(D_{i}<Q_{i}\right)}\left(Q_{i}+Q_{j}\right) \\
& b_{i j}^{2}=\operatorname{pr}\left(D_{i}+D_{j}>Q_{i}+Q_{j}\right) \mathrm{f}_{D_{i} \mid D_{i}+D_{j}>Q_{i}+Q_{j}}\left(Q_{i}\right) \\
& g_{i j}^{1}=\operatorname{pr}\left(D_{i}>Q_{i}\right) \mathrm{f}_{D_{i}+D_{j} \mid D_{i}>Q_{i}}\left(Q_{i}+Q_{j}\right) \\
& g_{i j}^{2}=\operatorname{pr}\left(D_{i}+D_{j}<Q_{i}+Q_{j}\right) \mathrm{f}_{D_{i} \mid D_{i}+D_{j}<Q_{i}+Q_{j}}\left(Q_{i}\right)
\end{aligned}
$$

The differentiation of Equation (A1) and rearrangement yields a characterization of the reaction function:

$$
\frac{\partial Q_{i}}{\partial Q_{j}}=-\frac{\left(v_{i}-c_{j i}\right) g_{i j}^{1}+\left(c_{i j}-\tau_{i j}-s_{i}\right) b_{i j}^{1}}{\left(v_{i}-s_{i}\right) a_{i}+\left(v_{i}-c_{j i}\right)\left(g_{i j}^{1}-g_{i j}^{2}\right)+\left(c_{i j}-\tau_{i j}-s_{i}\right)\left(b_{i j}^{1}-b_{i j}^{2}\right)}
$$

Because $a_{i}>b_{i j}^{2}, a_{i}>g_{i j}^{2}$, and the triangle inequality $c_{i j} \geq c_{j i}-\tau_{j i}$, we can get

$$
\begin{aligned}
& \left(v_{i}-s_{i}\right) a_{i}+\left(v_{i}-c_{j i}\right)\left(-g_{i j}^{2}\right)+\left(c_{i j}-\tau_{i j}-s_{i}\right)\left(-b_{i j}^{2}\right) \\
& >\left(v_{i}-s_{i}\right) a_{i}-\left(v_{i}-c_{j i}\right) a_{i}-\left(c_{i j}-\tau_{i j}-s_{i}\right) a_{i} \\
& =\left[c_{j i}-\left(c_{i j}-\tau_{i j}\right)\right] a_{i}
\end{aligned}
$$

Then it is easy to check that $\frac{\partial Q_{i}}{\partial Q_{j}}<0$ and $\left|\frac{\partial Q_{i}}{\partial Q_{j}}\right|<1$, when $c_{i j} \geq \tau_{i j}+s_{i}$ and $c_{j i} \leq v_{i}$.

The differentiation of Equation (A2) and rearrangement yields a characterization of the reaction function:

$$
\frac{\partial Q_{j}}{\partial Q_{i}}=-\frac{\left[\left(v_{j}-c_{i j}\right)-\hat{\lambda}_{j}\left(c_{i j}-s_{i}-\tau_{i j}\right)\right] g_{j i}^{1}+\left[\left(c_{j i}-s_{j}-\tau_{j i}\right)-\hat{\lambda}_{j}\left(v_{i}-c_{j i}\right)\right] b_{j i}^{1}}{\left\{\left(v_{j}-s_{j}\right) a_{j}+\left[\left(v_{j}-c_{i j}\right)-\hat{\lambda}_{j}\left(c_{i j}-s_{i}-\tau_{i j}\right)\right]\left(g_{j i}^{1}-g_{j i}^{2}\right)+\left[\left(c_{j i}-s_{j}-\tau_{j i}\right)-\hat{\lambda}_{j}\left(v_{i}-c_{j i}\right)\right]\left(b_{j i}^{1}-b_{j i}^{2}\right)\right\}}
$$

Because $a_{j}>b_{j i}^{2}, a_{j}>g_{j i}^{2}$, and the triangle inequality $c_{i j} \geq c_{j i}-\tau_{j i}$, we can get

$$
\begin{aligned}
& \left(v_{j}-s_{j}\right) a_{j}+\left[\left(v_{j}-c_{i j}\right)-\hat{\lambda}_{j}\left(c_{i j}-s_{i}-\tau_{i j}\right)\right]\left(-g_{j i}^{2}\right)+\left[\left(c_{j i}-s_{j}-\tau_{j i}\right)-\hat{\lambda}_{j}\left(v_{i}-c_{j i}\right)\right]\left(-b_{j i}^{2}\right) \\
& >\left(v_{j}-s_{j}\right) a_{j}-\left[\left(v_{j}-c_{i j}\right)-\hat{\lambda}_{j}\left(c_{i j}-s_{i}-\tau_{i j}\right)\right] a_{j}-\left[\left(c_{j i}-s_{j}-\tau_{j i}\right)-\hat{\lambda}_{j}\left(v_{i}-c_{j i}\right)\right] a_{j} \\
& =\left[c_{i j}-\left(c_{j i}-\tau_{j i}\right)\right] a_{j}+\left[\hat{\lambda}_{j}\left(c_{i j}-s_{i}-\tau_{i j}\right)+\hat{\lambda}_{j}\left(v_{i}-c_{j i}\right)\right] a_{j}
\end{aligned}
$$


Then it is easy to check that $\frac{\partial Q_{j}}{\partial Q_{i}}<0,\left|\frac{\partial Q_{j}}{\partial Q_{i}}\right|<1$ when $\frac{\hat{\lambda}_{j} v_{i}+\left(s_{j}+\tau_{j i}\right)}{1+\hat{\lambda}_{j}} \leq c_{j i} \leq v_{i}$ and $\tau_{i j}+s_{i} \leq c_{i j} \leq$ $\frac{v_{j}+\hat{\lambda}_{j}\left(s_{i}+\tau_{i j}\right)}{1+\hat{\lambda}_{j}}$.

Hence, we can get in the scenario NF, let $c_{12}^{N F} \in\left[s_{1}+\tau_{12}, \frac{v_{2}+\hat{\lambda}_{2}\left(s_{1}+\tau_{12}\right)}{1+\hat{\lambda}_{2}}\right], c_{21}^{N F} \in\left[\frac{\hat{\lambda}_{2} v_{1}+\left(s_{2}+\tau_{21}\right)}{1+\hat{\lambda}_{2}}, v_{1}\right]$, the reaction functions are monotonic, and the absolute value of the slope is less than 1 . Then there exist a unique Nash equilibrium for the order quantity of two retailers.

\section{Appendix A.2 Proof of Lemma 2}

Under the symmetric fairness concerns, both two retailer are fairness concerned, the initial order quantity $\left(Q_{1}^{F F}, Q_{2}^{F F}\right)$ is obtained by the Equation (4) for $i, j=1,2$.

The implicit function equations can be obtained as follows:

$$
\begin{aligned}
F^{\prime}\left(\lambda_{i}^{\prime}, \lambda_{j}^{\prime}, Q_{i}, Q_{j}\right) & =\left(1+\lambda_{i}^{\prime}\right)\left(v_{i}-s_{i}\right) \alpha_{i}-\left[\left(1+\lambda_{i}^{\prime}\right)\left(c_{i j}-s_{i}-\tau_{i j}\right)-\lambda_{i}^{\prime}\left(v_{j}-c_{i j}\right)\right] \beta_{i} \\
& +\left[\left(1+\lambda_{i}^{\prime}\right)\left(v_{i}-c_{j i}\right)-\lambda_{i}^{\prime}\left(c_{j i}-s_{j}-\tau_{j i}\right)\right] \gamma_{i}-\left(1+\lambda_{i}^{\prime}\right)\left(v_{i}-c\right) \\
G^{\prime}\left(\lambda_{i}^{\prime}, \lambda_{j}^{\prime}, Q_{i}, Q_{j}\right)= & \left(1+\lambda_{j}^{\prime}\right)\left(v_{j}-s_{j}\right) \alpha_{j}-\left[\left(1+\lambda_{j}^{\prime}\right)\left(c_{j i}-s_{j}-\tau_{j i}\right)-\lambda_{j}^{\prime}\left(v_{i}-c_{j i}\right)\right] \beta_{j} \\
& +\left[\left(1+\lambda_{j}^{\prime}\right)\left(v_{j}-c_{i j}\right)-\lambda_{j}^{\prime}\left(c_{i j}-s_{i}-\tau_{i j}\right)\right] \gamma_{j}-\left(1+\lambda_{j}^{\prime}\right)\left(v_{j}-c\right)
\end{aligned}
$$

Combined with the proof of Lemma 1, it is easy to check that $\frac{\partial Q_{i}}{\partial Q_{j}}<0,\left|\frac{\partial Q_{i}}{\partial Q_{j}}\right|<1$ when $\frac{\hat{\lambda}_{i}^{\prime} v_{j}+\left(s_{i}+\tau_{i j}\right)}{1+\hat{\lambda}_{i}^{\prime}} \leq c_{i j} \leq v_{j}$ and $\tau_{j i}+s_{j} \leq c_{j i} \leq \frac{v_{i}+\hat{\lambda}_{i}^{\prime}\left(s_{j}+\tau_{j i}\right)}{1+\hat{\lambda}_{i}^{\prime}}$. And we also can check that $\frac{\partial Q_{j}}{\partial Q_{i}}<0,\left|\frac{\partial Q_{j}}{\partial Q_{i}}\right|<1$ when $\frac{\hat{j}_{j}^{\prime} v_{i}+\left(s_{j}+\tau_{j i}\right)}{1+\hat{\lambda}_{j}^{\prime}} \leq c_{j i} \leq v_{i}$ and $\tau_{i j}+s_{i} \leq c_{i j} \leq \frac{v_{j}+\hat{\lambda}_{j}^{\prime}\left(s_{i}+\tau_{i j}\right)}{1+\hat{\lambda}_{j}^{\prime}}$. Since the expression $\frac{\left(s_{i}+\tau_{i j}\right)+\hat{\lambda}_{i}^{\prime} v_{j}}{1+\hat{\lambda}_{i}^{\prime}}$ is increasing in $\hat{\lambda}_{i}^{\prime}, \frac{v_{i}+\hat{\lambda}_{i}^{\prime}\left(s_{j}+\tau_{j i}\right)}{1+\hat{\lambda}_{i}^{\prime}}$ is decreasing in $\hat{\lambda}_{i}^{\prime}, \frac{\hat{\lambda}_{j}^{\prime} v_{i}+\left(s_{j}+\tau_{j i}\right)}{1+\hat{\lambda}_{j}^{\prime}}$ is increasing in $\hat{\lambda}_{j}^{\prime}$, and the expression $\frac{v_{j}+\hat{\lambda}_{j}^{\prime}\left(s_{i}+\tau_{i j}\right)}{1+\hat{\lambda}_{j}^{\prime}}$ is decreasing in $\hat{\lambda}_{j}^{\prime}$, we can get in the scenario FF, let $c_{i j}^{F F} \in\left[\frac{\left(s_{i}+\tau_{i j}\right)+\hat{\lambda}_{i}^{\prime} v_{j}}{1+\hat{\lambda}_{i}^{\prime}}, \frac{v_{j}+\hat{\lambda}_{j}^{\prime}\left(s_{i}+\tau_{i j}\right)}{1+\hat{\lambda}_{j}^{\prime}}\right]$, $i, j=1,2$, the reaction functions are monotonic, and the absolute value of the slope is less than 1 . Then there exist a unique Nash equilibrium for the order quantity of two retailers.

Appendix A.3 The Impacts of the Fairness Parameter on the Order Quantities and Profits of Two Retailers in the Scenario NF

The implicit function theorem is used to solve the impact of the fairness parameter on the order quantities and profits of the retailers. Combined with the proof of Lemma 1, the Jacobian determinant $J>0$.

The impacts of fairness parameter on the order quantities and total order quantity of retailers are:

$$
\begin{gathered}
\frac{\partial Q_{i}}{\partial \lambda_{j}}=\frac{1}{J} \frac{1}{1+\lambda_{j}}\left[\left(v_{i}-c_{j i}\right) \beta_{j}-\left(c_{i j}-s_{i}-\tau_{i j}\right) \gamma_{j}\right] \\
\times\left[\left(c_{i j}-s_{i}-\tau_{i j}\right) b_{i j}^{1}+\left(v_{i}-c_{j i}\right) g_{i j}^{1}\right] \\
\frac{\partial Q_{j}}{\partial \lambda_{j}}=-\frac{1}{J} \frac{1}{1+\lambda_{j}}\left[\left(v_{i}-c_{j i}\right) \beta_{j}-\left(c_{i j}-s_{i}-\tau_{i j}\right) \gamma_{j}\right] \\
\times\left[\left(v_{i}-s_{i}\right) a_{i}+\left(c_{i j}-s_{i}-\tau_{i j}\right)\left(b_{i j}^{1}-b_{i j}^{2}\right)+\left(v_{i}-c_{j i}\right)\left(g_{i j}^{1}-g_{i j}^{2}\right)\right] \\
\frac{\partial Q}{\partial \lambda_{j}}=-\frac{1}{J} \frac{1}{1+\lambda_{j}}\left[\left(v_{i}-c_{j i}\right) \beta_{j}-\left(c_{i j}-s_{i}-\tau_{i j}\right) \gamma_{j}\right] \\
\times\left[\left(v_{i}-s_{i}\right) a_{i}-\left(c_{i j}-s_{i}-\tau_{i j}\right) b_{i j}^{2}-\left(v_{i}-c_{j i}\right) g_{i j}^{2}\right]
\end{gathered}
$$


The impacts of fairness parameter on retailers' profits are:

$$
\begin{aligned}
& \frac{d \pi_{i}}{d \lambda_{j}}=\left(-\frac{1}{J}\right) \frac{1}{1+\lambda_{j}}\left[\left(v_{i}-c_{j i}\right) \beta_{j}-\left(c_{i j}-s_{i}-\tau_{i j}\right) \gamma_{j}\right]^{2} \\
& \times\left[\left(v_{i}-s_{i}\right) a_{i}+\left(c_{i j}-s_{i}-\tau_{i j}\right)\left(b_{i j}^{1}-b_{i j}^{2}\right)+\left(v_{i}-c_{j i}\right)\left(g_{i j}^{1}-g_{i j}^{2}\right)\right] \\
\frac{d \pi_{j}}{d \lambda_{j}}= & \left(-\frac{1}{J}\right) \frac{1}{1+\lambda_{j}} \hat{\lambda}_{j}\left[\left(v_{i}-c_{j i}\right) \beta_{j}-\left(c_{i j}-s_{i}-\tau_{i j}\right) \gamma_{j}\right]^{2} \\
\times & {\left[\left(v_{i}-s_{i}\right) a_{i}+\left(c_{i j}-s_{i}-\tau_{i j}\right)\left(b_{i j}^{1}-b_{i j}^{2}\right)+\left(v_{i}-c_{j i}\right)\left(g_{i j}^{1}-g_{i j}^{2}\right)\right] } \\
+ & \frac{1}{J} \frac{1}{1+\lambda_{j}}\left[\left(v_{j}-c_{i j}\right) \beta_{i}-\left(c_{j i}-s_{j}-\tau_{j i}\right) \gamma_{i}\right] \times\left[\left(v_{i}-c_{j i}\right) \beta_{j}-\left(c_{i j}-s_{i}-\tau_{i j}\right) \gamma_{j}\right] \\
\times & \times\left[\left(c_{i j}-s_{i}-\tau_{i j}\right) b_{i j}^{1}+\left(v_{i}-c_{j i}\right) g_{i j}^{1}\right]
\end{aligned}
$$

Appendix A.4 The Impacts of the Fairness Parameters on the Order Quantities and Profits of Two Retailers in the Scenario FF

Combined with the proof process of Lemma 2, the Jacobian determinant $J^{\prime}>0$. The impacts of the fairness parameters on the retailers' order quantities and the total order quantity are:

$$
\begin{aligned}
& \frac{\partial Q_{i}}{\partial \lambda_{i}^{\prime}}=-\frac{1}{J^{\prime}} \frac{1}{1+\lambda_{i}}\left[\left(v_{j}-c_{i j}\right) \beta_{i}-\left(c_{j i}-s_{j}-\tau_{j i}\right) \gamma_{i}\right] \\
& \times\left[\begin{array}{l}
\left(1+\lambda_{j}^{\prime}\right)\left(v_{j}-s_{j}\right) a_{j}+\left[\left(1+\lambda_{j}^{\prime}\right)\left(c_{j i}-s_{j}-\tau_{j i}\right)-\lambda_{j}^{\prime}\left(v_{i}-c_{j i}\right)\right]\left(b_{j i}^{1}-b_{j i}^{2}\right) \\
+\left[\left(1+\lambda_{j}^{\prime}\right)\left(v_{j}-c_{i j}\right)-\lambda_{j}^{\prime}\left(c_{i j}-s_{i}-\tau_{i j}\right)\right]\left(g_{j i}^{1}-g_{j i}^{2}\right)
\end{array}\right] \\
& \frac{\partial Q_{j}}{\partial \lambda_{i}^{\prime}}=\frac{1}{J^{\prime}} \frac{1}{1+\lambda_{i}^{\prime}}\left[\left(v_{j}-c_{i j}\right) \beta_{i}-\left(c_{j i}-s_{j}-\tau_{j i}\right) \gamma_{i}\right] \\
& \times\left[\begin{array}{l}
{\left[\left(1+\lambda_{j}^{\prime}\right)\left(c_{j i}-s_{j}-\tau_{j i}\right)-\lambda_{j}^{\prime}\left(v_{i}-c_{j i}\right)\right] b_{j i}^{1}} \\
+\left[\left(1+\lambda_{j}^{\prime}\right)\left(v_{j}-c_{i j}\right)-\lambda_{j}^{\prime}\left(c_{i j}-s_{i}-\tau_{i j}\right)\right] g_{j i}^{1}
\end{array}\right] \\
& \frac{\partial Q}{\partial \lambda_{i}^{\prime}}=-\frac{1}{J^{\prime}} \frac{1}{1+\lambda_{i}^{\prime}}\left[\left(v_{j}-c_{i j}\right) \beta_{i}-\left(c_{j i}-s_{j}-\tau_{j i}\right) \gamma_{i}\right] \\
& \times\left[\begin{array}{l}
\left(1+\lambda_{j}^{\prime}\right)\left(v_{j}-s_{j}\right) a_{j}-\left[\left(1+\lambda_{j}^{\prime}\right)\left(c_{j i}-s_{j}-\tau_{j i}\right)-\lambda_{j}^{\prime}\left(v_{i}-c_{j i}\right)\right] b_{j i}^{2} \\
+\left[\left(1+\lambda_{j}^{\prime}\right)\left(v_{j}-c_{i j}\right)-\lambda_{j}^{\prime}\left(c_{i j}-s_{i}-\tau_{i j}\right)\right] g_{j i}^{2}
\end{array}\right]
\end{aligned}
$$

The impacts of fairness parameters on retailers' profits are:

$$
\begin{aligned}
\frac{d \pi_{i}}{d \lambda_{i}^{\prime}}= & \hat{\lambda}_{i}^{\prime}\left(\left(v_{j}-c_{i j}\right) \beta_{i}-\left(c_{j i}-s_{j}-\tau_{j i}\right) \gamma_{i}\right) \times\left(-\frac{1}{J^{\prime}}\right) \frac{1}{1+\lambda_{i}^{\prime}}\left[\left(v_{j}-c_{i j}\right) \beta_{i}-\left(c_{j i}-s_{j}-\tau_{j i}\right) \gamma_{i}\right] \\
\times & {\left[\begin{array}{l}
\left.\left(1+\lambda_{j}^{\prime}\right)\left(v_{j}-s_{j}\right) a_{j}+\left[\left(1+\lambda_{j}^{\prime}\right)\left(c_{j i}-s_{j}-\tau_{j i}\right)-\lambda_{j}^{\prime}\left(v_{i}-c_{j i}\right)\right]\left(b_{j i}^{1}-b_{j i}^{2}\right)\right] \\
+\left[\left(1+\lambda_{j}^{\prime}\right)\left(v_{j}-c_{i j}\right)-\lambda_{j}^{\prime}\left(c_{i j}-s_{i}-\tau_{i j}\right)\right]\left(g_{j i}^{1}-g_{j i}^{2}\right)
\end{array}\right] } \\
+ & \left(\left(v_{i}-c_{j i}\right) \beta_{j}-\left(c_{i j}-s_{i}-\tau_{i j}\right) \gamma_{j}\right) \times \frac{1}{J^{\prime}} \frac{1}{1+\lambda_{i}^{\prime}}\left[\left(v_{j}-c_{i j}\right) \beta_{i}-\left(c_{j i}-s_{j}-\tau_{j i}\right) \gamma_{i}\right] \\
\times & {\left[\begin{array}{l}
{\left[\left(1+\lambda_{j}^{\prime}\right)\left(c_{j i}-s_{j}-\tau_{j i}\right)-\lambda_{j}^{\prime}\left(v_{i}-c_{j i}\right)\right] b_{j i}^{1}} \\
+\left[\left(1+\lambda_{j}^{\prime}\right)\left(v_{j}-c_{i j}\right)-\lambda_{j}^{\prime}\left(c_{i j}-s_{i}-\tau_{i j}\right)\right] g_{j i}^{1}
\end{array}\right] }
\end{aligned}
$$




$$
\begin{aligned}
\frac{d \pi_{j}}{d \lambda_{i}^{\prime}}= & \left(\left(v_{j}-c_{i j}\right) \beta_{i}-\left(c_{j i}-s_{j}-\tau_{j i}\right) \gamma_{i}\right) \times\left(-\frac{1}{J^{\prime}}\right) \frac{1}{1+\lambda_{i}}\left[\left(v_{j}-c_{i j}\right) \beta_{i}-\left(c_{j i}-s_{j}-\tau_{j i}\right) \gamma_{i}\right] \\
\times & {\left[\begin{array}{l}
\left(1+\lambda_{j}^{\prime}\right)\left(v_{j}-s_{j}\right) a_{j}+\left[\left(1+\lambda_{j}^{\prime}\right)\left(c_{j i}-s_{j}-\tau_{j i}\right)-\lambda_{j}^{\prime}\left(v_{i}-c_{j i}\right)\right]\left(b_{j i}^{1}-b_{j i}^{2}\right) \\
+\left[\left(1+\lambda_{j}^{\prime}\right)\left(v_{j}-c_{i j}\right)-\lambda_{j}^{\prime}\left(c_{i j}-s_{i}-\tau_{i j}\right)\right]\left(g_{j i}^{1}-g_{j i}^{2}\right)
\end{array}\right] } \\
+ & \hat{\lambda}_{j}^{\prime}\left(\left(v_{i}-c_{j i}\right) \beta_{j}-\left(c_{i j}-s_{i}-\tau_{i j}\right) \gamma_{j}\right) \times \frac{1}{J^{\prime}} \frac{1}{1+\lambda_{i}^{\prime}}\left[\left(v_{j}-c_{i j}\right) \beta_{i}-\left(c_{j i}-s_{j}-\tau_{j i}\right) \gamma_{i}\right] \\
\times & {\left[\begin{array}{l}
{\left[\left(1+\lambda_{j}^{\prime}\right)\left(c_{j i}-s_{j}-\tau_{j i}\right)-\lambda_{j}^{\prime}\left(v_{i}-c_{j i}\right)\right] b_{j i}^{1}} \\
+\left[\left(1+\lambda_{j}^{\prime}\right)\left(v_{j}-c_{i j}\right)-\lambda_{j}^{\prime}\left(c_{i j}-s_{i}-\tau_{i j}\right)\right] g_{j i}^{1}
\end{array}\right] }
\end{aligned}
$$

Appendix A.5 Proof of Proposition 1

Combined with the proof process of Lemma 1, it can be concluded that: when $\eta_{1}=0$, we get $\frac{\partial Q_{1}^{N F}}{\partial \lambda_{2}}=\frac{\partial Q_{2}^{N F}}{\partial \lambda_{2}}=0$; when $\eta_{1}>0$, we get $\frac{\partial Q_{1}^{N F}}{\partial \lambda_{2}}>0, \frac{\partial Q_{2}^{N F}}{\partial \lambda_{2}}<0$ and $\frac{\partial Q^{N F}}{\partial \lambda_{2}}<0$; when $\eta_{1}<0$, we get $\frac{\partial Q_{1}^{N F}}{\partial \lambda_{2}}<0, \frac{\partial Q_{2}^{N F}}{\partial \lambda_{2}}>0$ and $\frac{\partial Q^{N F}}{\partial \lambda_{2}}>0$. Q.E.D.

\section{Appendix A.6 Proof of Proposition 2}

From the impacts of the fairness parameters on the profits of two retailers in the scenario NF, we find: $\frac{d \pi_{1}^{N F}}{d \lambda_{2}} \leq 0$; in the condition $C_{1}^{N F}, \frac{d \pi_{2}^{N F}}{d \lambda_{2}} \leq 0$, in the condition $C_{2}^{N F}, \frac{d \pi_{2}^{N F}}{d \lambda_{2}}>0$. The conditions $C_{1}^{N F}$ and $C_{2}^{N F}$ are expressed as follows.

$$
\begin{aligned}
& C_{1}^{N F}: \eta_{1} \geq 0 \text { and } \eta_{2}<\eta_{3} \text {, or } \eta_{1}<0 \text { and } \eta_{2}>\eta_{3} . \\
& C_{2}^{N F}: \eta_{1}>0 \text { and } \eta_{2}>\eta_{3} \text {, or } \eta_{1}<0 \text { and } \eta_{2}<\eta_{3} .
\end{aligned}
$$

where

$$
\eta_{3}:=\hat{\lambda}_{2} \times \eta_{1} \times \frac{\left(v_{1}-s_{1}\right) a_{1}+\left(v_{1}-c_{21}\right)\left(g_{12}^{1}-g_{12}^{2}\right)+\left(c_{12}-\tau_{12}-s_{1}\right)\left(b_{12}^{1}-b_{12}^{2}\right)}{\left[\left(v_{1}-c_{21}\right) g_{12}^{1}+\left(c_{12}-\tau_{12}-s_{1}\right) b_{12}^{1}\right]}
$$

Q.E.D.

\section{Appendix A.7 Proof of Theorem 1}

In the scenario $\mathrm{NF}, \hat{\lambda}_{2} \in[0,1)$. When $\lambda_{2}=0$, the scenario NF reduces to the scenario NN. Combined with proposition 2, it can be concluded that: $\pi_{1}^{N F} \leq \pi_{1}^{N N}$ is always obtained; as long as the condition $C_{1}^{N F}$ is satisfied, then $\pi_{2}^{N F} \leq \pi_{2}^{N N}$, and as long as the condition $C_{2}^{N F}$ is satisfied, then $\pi_{2}^{N F}>\pi_{2}^{N N}$. Q.E.D.

\section{Appendix A.8 Proof of Proposition 3}

Combined with the proof of Lemma 2, it can be seen that: when $\eta_{i} \times \eta_{j} \leq 0$, we get $\frac{\partial Q_{i}^{F F}}{\partial \lambda_{i}^{\prime}} \frac{\partial Q_{i}^{F F}}{\partial \lambda_{j}^{\prime}} \geq 0$, $\frac{\partial Q_{j}^{F F}}{\partial \lambda_{i}^{\prime}} \frac{\partial Q_{j}^{F F}}{\partial \lambda_{j}^{\prime}} \geq 0$; when $\eta_{i} \times \eta_{j}>0$, we get $\frac{\partial Q_{i}^{F F}}{\partial \lambda_{i}^{\prime}} \frac{\partial Q_{i}^{F F}}{\partial \lambda_{j}^{\prime}}<0, \frac{\partial Q_{j}^{F F}}{\partial \lambda_{i}^{\prime}} \frac{\partial Q_{j}^{F F}}{\partial \lambda_{j}^{\prime}}<0, i, j=1$, 2. Q.E.D.

\section{Appendix A.9 Proof of Proposition 4}

From the impacts of the fairness parameters on the profits of two retailers in the scenario FF, we find: in the condition $C_{5} \cup C_{6}\left(C_{9} \cup C_{10}\right)$, the tendency for the profit of retailer 1 (retailer 2) with increased $\lambda_{i}^{\prime}$ is opposite to that with increased $\lambda_{j}^{\prime}$; in the condition $C_{3} \cup C_{4}\left(C_{7} \cup C_{8}\right)$, the tendency for the profit of retailer 1 (retailer 2) with increased $\lambda_{i}^{\prime}$ is the same as that with increased $\lambda_{j}^{\prime}$.

The conditions $C_{m}, m=3,4,5,6,7,8,9,10$ are expressed as follows.

$C_{3}: \eta_{1}>0$ and $\eta_{2}<0$, or $\eta_{1}<0$ and $\eta_{2}>0$, or $\eta_{4}>\eta_{1}>0$ and $\eta_{5}>\eta_{2}>0$, or $\eta_{4}<\eta_{1}<0$ and $\eta_{5}<\eta_{2}<0$. 
$C_{4}: \eta_{1}>\eta_{4}>0$ and $\eta_{2}>\eta_{5}>0$, or $\eta_{1}<\eta_{4}<0$ and $\eta_{2}<\eta_{5}<0$.

$C_{5}: \eta_{4}>\eta_{1}>0$ and $\eta_{2}>\eta_{5}>0$, or $\eta_{4}<\eta_{1}<0$ and $\eta_{2}<\eta_{5}<0$.

$C_{6}: \eta_{1}>\eta_{4}>0$ and $\eta_{5}>\eta_{2}>0$, or $\eta_{1}<\eta_{4}<0$ and $\eta_{5}<\eta_{2}<0$.

$C_{7}: \eta_{1}>0$ and $\eta_{2}<0$, or $\eta_{1}<0$ and $\eta_{2}>0$, or $\eta_{6}>\eta_{1}>0$ and $\eta_{7}>\eta_{2}>0$, or $\eta_{6}<\eta_{1}<0$ and $\eta_{7}<\eta_{2}<0$.

$C_{8}: \eta_{1}>\eta_{6}>0$ and $\eta_{2}>\eta_{7}>0$, or $\eta_{1}<\eta_{6}<0$ and $\eta_{2}<\eta_{7}<0$.

$C_{9}: \eta_{6}>\eta_{1}>0$ and $\eta_{2}>\eta_{7}>0$, or $\eta_{6}<\eta_{1}<0$ and $\eta_{2}<\eta_{7}<0$.

$C_{10}: \eta_{1}>\eta_{6}>0$ and $\eta_{7}>\eta_{2}>0$, or $\eta_{1}<\eta_{6}<0$ and $\eta_{7}<\eta_{2}<0$.

where

$$
\begin{aligned}
& \left(v_{2}-s_{2}\right) a_{2}+\left[\left(c_{21}-s_{2}-\tau_{21}\right)-\hat{\lambda}_{2}^{\prime}\left(v_{1}-c_{21}\right)\right]\left(b_{21}^{1}-b_{21}^{2}\right) \\
& \eta_{4}:=\hat{\lambda}_{1}^{\prime} \times \eta_{2} \times \frac{+\left[\left(v_{2}-c_{12}\right)-\hat{\lambda}_{2}^{\prime}\left(c_{12}-s_{1}-\tau_{12}\right)\right]\left(g_{21}^{1}-g_{21}^{2}\right)}{\left[\left[\left(c_{21}-s_{2}-\tau_{21}\right)-\hat{\lambda}_{2}^{\prime}\left(v_{1}-c_{21}\right)\right] b_{21}^{1}+\left[\left(v_{2}-c_{12}\right)-\hat{\lambda}_{2}^{\prime}\left(c_{12}-s_{1}-\tau_{12}\right)\right] g_{21}^{1}\right]} \\
& \left(v_{1}-s_{1}\right) a_{1}+\left[\left(c_{12}-\tau_{12}-s_{1}\right)-\hat{\lambda}_{1}^{\prime}\left(v_{2}-c_{12}\right)\right]\left(b_{12}^{1}-b_{12}^{2}\right) \\
& \eta_{5}:=\frac{1}{\hat{\lambda}_{1}^{\prime}} \times \eta_{1} \times \frac{+\left[\left(v_{1}-c_{21}\right)-\hat{\lambda}_{1}^{\prime}\left(c_{21}-s_{2}-\tau_{21}\right)\right]\left(g_{12}^{1}-g_{12}^{2}\right)}{\left[\left[\left(c_{12}-\tau_{12}-s_{1}\right)-\hat{\lambda}_{1}^{\prime}\left(v_{2}-c_{12}\right)\right] b_{12}^{1}+\left[\left(v_{1}-c_{21}\right)-\hat{\lambda}_{1}^{\prime}\left(c_{21}-s_{2}-\tau_{21}\right)\right] g_{12}^{1}\right]} \\
& \left(v_{2}-s_{2}\right) a_{2}+\left[\left(c_{21}-s_{2}-\tau_{21}\right)-\hat{\lambda}_{2}^{\prime}\left(v_{1}-c_{21}\right)\right]\left(b_{21}^{1}-b_{21}^{2}\right) \\
& \eta_{6}:=\frac{1}{\hat{\lambda}_{2}^{\prime}} \times \eta_{2} \times \frac{+\left[\left(v_{2}-c_{12}\right)-\hat{\lambda}_{2}^{\prime}\left(c_{12}-s_{1}-\tau_{12}\right)\right]\left(g_{21}^{1}-g_{21}^{2}\right)}{\left[\left[\left(c_{21}-s_{2}-\tau_{21}\right)-\hat{\lambda}_{2}^{\prime}\left(v_{1}-c_{21}\right)\right] b_{21}^{1}+\left[\left(v_{2}-c_{12}\right)-\hat{\lambda}_{2}^{\prime}\left(c_{12}-s_{1}-\tau_{12}\right)\right] g_{21}^{1}\right]} \\
& \left(v_{1}-s_{1}\right) a_{1}+\left[\left(c_{12}-\tau_{12}-s_{1}\right)-\hat{\lambda}_{1}^{\prime}\left(v_{2}-c_{12}\right)\right]\left(b_{12}^{1}-b_{12}^{2}\right) \\
& \eta_{7}:=\hat{\lambda}_{2}^{\prime} \times \eta_{1} \times \frac{+\left[\left(v_{1}-c_{21}\right)-\hat{\lambda}_{1}^{\prime}\left(c_{21}-s_{2}-\tau_{21}\right)\right]\left(g_{12}^{1}-g_{12}^{2}\right)}{\left[\left[\left(c_{12}-\tau_{12}-s_{1}\right)-\hat{\lambda}_{1}^{\prime}\left(v_{2}-c_{12}\right)\right] b_{12}^{1}+\left[\left(v_{1}-c_{21}\right)-\hat{\lambda}_{1}^{\prime}\left(c_{21}-s_{2}-\tau_{21}\right)\right] g_{12}^{1}\right]}
\end{aligned}
$$

In the condition $C_{3}, \frac{d \pi_{1}^{F F}}{d \lambda_{1}^{\prime}} \leq 0, \frac{d \pi_{1}^{F F}}{d \lambda_{2}^{\prime}} \leq 0$; in the condition $C_{4}, \frac{d \pi_{1}^{F F}}{d \lambda_{1}^{\prime}}>0, \frac{d \pi_{1}^{F F}}{d \lambda_{2}^{\prime}}>0$; in the condition $C_{5}, \frac{d \pi_{1}^{F F}}{d \lambda_{1}^{\prime}} \leq 0, \frac{d \pi_{1}^{F F}}{d \lambda_{2}^{\prime}}>0$; in the condition $C_{6}, \frac{d \pi_{1}^{F F}}{d \lambda_{1}^{\prime}}>0, \frac{d \pi_{1}^{F F}}{d \lambda_{2}^{\prime}} \leq 0$.

In the condition $C_{7}, \frac{d \pi_{2}^{F F}}{d \lambda_{1}^{\prime}} \leq 0, \frac{d \pi_{2}^{F F}}{d \lambda_{2}^{\prime}} \leq 0$; in the condition $C_{8}, \frac{d \pi_{2}^{F F}}{d \lambda_{1}^{\prime}}>0, \frac{d \pi_{2}^{F F}}{d \lambda_{2}^{\prime}}>0$; in the condition $C_{9}, \frac{d \pi_{2}^{F F}}{d \lambda_{1}^{\prime}} \leq 0, \frac{d \pi_{2}^{F F}}{d \lambda_{2}^{\prime}}>0$, in the condition $C_{10}, \frac{d \pi_{2}^{F F}}{d \lambda_{1}^{\prime}}>0, \frac{d \pi_{2}^{F F}}{d \lambda_{2}^{\prime}} \leq 0$. Q.E.D.

\section{Appendix A.10 Proof of Theorem 2}

In the scenario $\mathrm{FF}, \hat{\lambda}_{1}^{\prime}, \hat{\lambda}_{2}^{\prime} \in[0,1)$. When $\lambda_{1}^{\prime}=\lambda_{2}^{\prime}=0$, the scenario FF can reduce to the scenario NN. Combined with the proof of Proposition 4, comparing the profits in the scenario FF with that the scenario $\mathrm{NN}$, it can be seen that under symmetric fairness concerns, there are the following cases about the retailer's profits, compared with the scenario of completely rationality: in the condition $C_{5} \cup C_{6}\left(C_{9} \cup C_{10}\right)$, two retailers may has higher or lower profits; in the condition $C_{4}\left(C_{8}\right)$, retailer 1(retailer 2) has a higher profit; in the condition $C_{3}\left(C_{7}\right)$, retailer 1(retailer 2) has a lower profit. Q.E.D.

\section{Appendix A.11 Proof of Theorem 3}

In the scenario $\mathrm{FF}, \hat{\lambda}_{1}^{\prime}, \hat{\lambda}_{2}^{\prime} \in[0,1)$. When $\lambda_{1}^{\prime}=0$, the scenario FF reduces to the scenario NF. We can compare the profits in the scenario FF with that in the scenario NF. It can be seen that under symmetric fairness concerns, there are the following cases about the retailer's profits, compared with asymmetric fairness concerns: in the condition $C_{2}^{F F}\left(C_{4}^{F F}\right)$, the retailer 1 (the retailer 2) has a higher profit; in the condition $C_{1}^{F F}\left(C_{3}^{F F}\right)$, retailer 1 (retailer 2) has a lower profit.

The conditions $C_{n}^{F F}, n=1,2,3,4$ are expressed as follows.

$$
C_{1}^{F F}: \eta_{2} \geq 0 \text { and } \eta_{1}<\eta_{4} \text {, or } \eta_{2}<0 \text { and } \eta_{1}>\eta_{4} \text {. }
$$


$C_{2}^{F F}: \eta_{2}>0$ and $\eta_{1}>\eta_{4}$, or $\eta_{2}<0$ and $\eta_{1}<\eta_{4}$.

$C_{3}^{F F}: \eta_{2} \geq 0$ and $\eta_{1}<\eta_{6}$, or $\eta_{2}<0$ and $\eta_{1}>\eta_{6}$.

$C_{4}^{F F}: \eta_{2}>0$ and $\eta_{1}>\eta_{6}$, or $\eta_{2}<0$ and $\eta_{1}<\eta_{6}$.

In the condition $C_{1}^{F F}, \pi_{1}^{F F} \leq \pi_{1}^{N F}$; in the condition $C_{2}^{F F}, \pi_{1}^{F F}>\pi_{1}^{N F}$; in the condition $C_{3}^{F F}$, $\pi_{2}^{F F} \leq \pi_{2}^{N F}$; in the condition $C_{4}^{F F}, \pi_{2}^{F F}>\pi_{2}^{N F}$. Q.E.D.

\section{References}

1. Kleindorfer, P.R.; Singhal, K.; Wassenshove, L.N.V. Sustainable operations management. Prod. Oper. Manag. 2005, 14, 482-492. [CrossRef]

2. Krishnan, K.S.; Rao, V.R.K. Inventory control in N warehouses. J. Ind. Eng. 1965, 16, 212-215.

3. Karmarkar, U.S. The multilocation multiperiod inventory problem: Bounds and approximations. Manag. Sci. 1987, 33, 86-94. [CrossRef]

4. Robinson, L.W. Optimal and approximate policies in multiperiod, multilocation inventory models with transshipments. Oper. Res. 1990, 38, 278-295. [CrossRef]

5. Rudi, N.; Kapur, S.; Pyke, D.F. A two-location inventory model with transshipment and local decision making. Manag. Sci. 2001, 47, 1668-1680. [CrossRef]

6. Dong, L.; Rudi, N. Who benefits from transshipment? Exogenous vs. endogenous wholesale prices. Manag. Sci. 2004, 50, 645-657. [CrossRef]

7. Shao, J.; Kriahnan, H.; Mccormock, S.T. Incentives for transshipment in a supply chain with decentralized retailers. Manuf. Serv. Oper. Manag. 2011, 13, 361-372. [CrossRef]

8. Li, R.; Ryan, J.K.; Zeng, Z. Coordination in a single-supplier, multi-retailer distribution system: Supplier-facilitated transshipments. Prod. Oper. Manag. 2017, 26, 784-801. [CrossRef]

9. Sosic, G. Transshipment of inventories among retailers: Myopic vs. farsighted Stability. Manag. Sci. 2006, 52, 1493-1508. [CrossRef]

10. Yan, X.H.; Zhao, H. Inventory sharing and coordination among $\mathrm{N}$ independent retailers. Eur. J. Oper. Res. 2015, 243, 576-587. [CrossRef]

11. Ariño, A.; Ring, P.S. The role of fairness in alliance formation. Strateg. Manag. J. 2010, 31, 1054-1087. [CrossRef]

12. Fehr, E.; Schdimt, K.M. A theory of fairness, competition, and cooperation. Q. J. Econ. 1999, 114, 817-868. [CrossRef]

13. Reuer, J.J.; Lahiri, N. Searching for alliance partners: Effects of geographic distance on the formation of R\&D collaborations. Organ. Sci. 2014, 25, 283-298.

14. Blevins, D.P.; Ragozzino, R. An examination of the effects of venture capitalists on the alliance formation activity of entrepreneurial firms. Strateg. Manag. J. 2018, 39, 2075-2091. [CrossRef]

15. Gu, Q.; $\mathrm{Lu}, \mathrm{X}$. Unraveling the mechanisms of reputation and alliance formation: A study of venture capital syndication in China. Strateg. Manag. J. 2014, 35, 739-750. [CrossRef]

16. Bos, B.; Faems, D.; Noseleit, F. Alliance concentration in multinational companies-examining alliance portfolios, firm structure, and firm performance. Strateg. Manag. J. 2017, 38, 2298-2309. [CrossRef]

17. Wassmer, U.; Li, S.; Madhok, A. Resource ambidexterity through alliance portfolios and firm performance. Strateg. Manag. J. 2017, 38, 384-394. [CrossRef]

18. Jiang, H.; Xia, J.; Cannella, A.A.; Xiao, T. Do ongoing networks block out new friends? Reconciling the embeddedness constraint dilemma on new alliance partner addition. Strateg. Manag. J. 2018, 39, 217-241. [CrossRef]

19. Abouee-mehrizi, H.; Berman, O.; Sharma, S. Optimal joint replenishment and transshipment policies in a multi-period inventory system with lost sales. Oper. Res. 2015, 63, 342-350. [CrossRef]

20. Glazbrook, K.; Paterson, C.; Rauscher, S.; Archibald, T. Benefits of hybrid lateral transshipments in multi-item inventory systems under periodic replenishment. Prod. Oper. Manag. 2015, 24, 311-324. [CrossRef]

21. Zhao, F.G.; Wu, D.S.; Liang, L.; Dolgui, A. Lateral inventory transshipment problem in online-to-offline supply chain. Int. J. Pro. Res. 2016, 54, 1951-1963. [CrossRef]

22. Liu, Y.; Huang, Y.; Luo, Y.; Zhao, Y. How does justice matter in achieving buyer-supplier relationship performance? J. Oper. Manag. 2012, 30, 355-367. [CrossRef] 
23. Slikker, M.; Fransoo, J.; Wouters, M. Cooperation between multiple news-vendors with transshipments. Eur. J. Oper. Res. 2005, 167, 370-380. [CrossRef]

24. Kumar, N.; Scheer, L.K.; Steenkamp, J.B.E.M. The effects of supplier fairness on vulnerable resellers. J. Mark. Res. 1995, 3, 54-65. [CrossRef]

25. Griffith, D.A.; Harvey, M.J.; Lusch, R.F. Social exchange in supply chain relationships: The resulting benefits of procedural and distributive justice. J. Oper. Manag. 2006, 24, 85-98. [CrossRef]

26. Cui, T.H.; Raju, J.S.; Zhang, Z.J. Fairness and channel coordination. Manag. Sci. 2007, 53, 1303-1314.

27. Ho, T.H.; Su, X.; Wu, Y. Distributional and peer-induced fairness in supply chain contract design. Prod. Oper. Manag. 2014, 23, 161-175. [CrossRef]

28. Nie, T.F.; Du, S.F. Dual-fairness supply chain with quantity discount contracts. Eur. J. Oper. Res. 2017, 258, 491-500. [CrossRef]

29. Zhang, L.H.; Xue, B.W.; Liu, X.Y. Carbon emission reduction with regard to retailer's fairness concern and subsidies. Sustainability 2017, 10, 1209. [CrossRef]

30. Ambrose, M.L.; Schminke, M. The Role of overall justice judgments in organizational justice research: A test of mediation. J. Appl. Psychol. 2009, 94, 491-500. [CrossRef]

31. Barclay, L.J.; Kiefer, T. Approach or Avoid? Exploring overall justice and the differential effects of positive and negative emotions. J. Manag. 2014, 40, 1857-1898. [CrossRef]

32. Aryee, S.; Walumbwa, F.O.; Mondejar, R.; Chu, C.W.L. Accounting for the influence of overall justice on Job performance: Integrating self-determination and social exchange theories. J. Manag. Stud. 2015, 52, 231-252. [CrossRef]

33. Tagaras, G. Effects of pooling on the optimization and service levels of two-location inventory systems. IIE Trans. 1989, 21, 250-257. [CrossRef]

34. Ho, T.H.; Zhang, J. Designing pricing contracts for boundedly rational customers: Does the framing of the fixed fee matter? Manag. Sci. 2008, 54, 686-700. [CrossRef]

35. Kahneman, D.; Tversky, A. Prospect theory: An analysis of decision under risk. Econometrica 1979, 47, 263-291. [CrossRef] 